\title{
Las respuestas de la Unión Europea a ciertos avatares en el siglo XXI que determinan el proceso de su conformación
}

\author{
The Responses of the European Union to \\ Certain Avatars in the XXI Century that \\ Determine the Process of its Formation
}

\author{
Sagrario Morán Blanco ${ }^{1}$ \\ Universidad Rey Juan Carlos (España) \\ Cástor M. Díaz Barrado ${ }^{2}$ \\ Universidad Rey Juan Carlos (España)
}

Recibido: 07-09-20

Aceptado: 06-10-20

\begin{abstract}
${ }^{1}$ (mariasagrario.moran@urjc.es). Catedrática de Relaciones Internacionales en la Universidad Rey Juan Carlos de Madrid. Este trabajo se ha realizado en el marco del Grupo de Investigación de Alto Rendimiento en Libertad, Seguridad y Ciudadanía en el Orden Internacional (INTERCIVITAS), de la Universidad Rey Juan Carlos. Sus líneas de Investigación se centran fundamentalmente en cuestiones de Defensa, Seguridad, Terrorismo, Delincuencia Organizada, así como Cuestiones Medioambientales y Fuentes de Energía. Entre sus últimas publicaciones destacan: 1) "España-Portugal: Hacia una seguridad compartida en sectores prioritarios de la relación bilateral", Documento de Investigación 03/2019 del Instituto Español de Estudios Estratégicos del Ministerio de Defensa. Lugar de publicación: http://www. ieee.es/Galerias/fichero/docs_investig/2019/DIEEEINV03-2018Portugal.pdf. 2) "Child, early and forced marriage: Policies and Legal Instruments for its eradiction in the International Society", en el libro titulado Sustainable Development Goals. Goal 5: Gender Equality. Thomson Reuters Aranzadi, Madrid, 2019. 3) "El Trabajo decente en la UE: Políticas y Normas", Nueva Revista Española de Derecho del Trabajo, no 206, Febrero 2018. Y 4) "Combatting against Terrorism and International Crime as goals of Agenda 2030. Policies and Instrument proposed from International Law", en el libro titulado Sustainable Development Goals: Goal 16. Peace, Justice and strong institutions, Thomson Reuters Aranzadi, Madrid, 2018.

ORCID: https://orcid.org/0000-0001-9479-9623.

2 (castormiguel.diaz@urjc.es). Catedrático de Derecho Internacional Público y Relaciones Internacionales de la Universidad Rey Juan Carlos de Madrid. Este trabajo se ha realizado en el marco del Grupo de Investigación de Alto Rendimiento en Libertad, Seguridad y Ciudadanía en el Orden Internacional (INTERCIVITAS), de la Universidad Rey Juan Carlos. Entre sus líneas de investigación caben resaltar: derechos humanos, desarrollo sostenible, integración en América Latina y el Caribe y la seguridad en el orden internacional. Entre sus últimas publicaciones destacan: "La Cumbre de las Américas: un espacio para la cooperación sin apenas proyección normativa", Revista Española de Derecho Internacional, vol. 71, nº 1, 2019, pp. 63-88; "Acabar con la pobreza: una cuestión de derechos humanos", Tiempo de paz, no. 132, 2019, pp. 42-49; "El conflicto en Colombia: Derechos Humanos, beligerancia y uso de la fuerza", Anuario de los Cursos de Derechos Humanos de Donostia-San Sebastián, vol. XVII/coord. por Juan Soroeta Liceras, y Nicolás Alonso Moreda, Aranzadi, Madrid, 2017, pp. 117-140; América en Busca de la Integración: Rasgos y Principios desde la Óptica del Derecho Internacional, Tirant lo Blanch, Valencia, 2018.
\end{abstract}

ORCID: https://orcid.org/0000-0003-2285-830X. 


\title{
Resumen
}

El presente artículo tiene como propósito examinar las respuestas de la Unión Europea a las crisis y avatares a los que se enfrenta habitualmente en el proceso de su conformación política. Con la apertura del nuevo siglo, la UE ha tenido que dar solución a retos y desafíos que alertaban sobre la solidez de la propia construcción europea. En particular, este trabajo analiza cuatro momentos de crisis que tienen orígenes diferentes y consecuencias distintas. Por orden cronológico son los siguientes. Los dos primeros discurrieron en el primer decenio del siglo XXI: el proceso de Constitución europea y la crisis financiera mundial, que afectaron de manera primordial a aspectos políticos y económicos de la integración europea. Los dos segundos se enmarcan en el segundo decenio: el Brexit y la Pandemia de la Covid-19, y apresan cuestiones relativas a la salud, aunque no solo, y a la participación de los Estados miembros en el esquema de integración.

Palabras-clave: Unión Europea, Integración, Crisis Económica y Financiera, Constitución Europea, Brexit, Pandemia.

\begin{abstract}
The goal of this article is to examine the responses of the European Union to the crises and vicissitudes that it regularly faces in the process of its political formation. With the beginning of the new century, the EU has had to solve challenges and objectives that warned about the strength of the European construction itself. In particular, this paper analyses four moments of crisis that have different origins and different consequences. In chronological order they are the following. The first two took place in the first decade of the 21st century: The European Constitution process and the global financial crisis, and the primarily affected political and economic aspects of European integration. The two second are framed in the second decade: Brexit and the Covid-19 Pandemic, and concern issues related to the health, but not only, and to the participation of the member states in the integration process.
\end{abstract}

Key-words: European Union, Integration, Economic and Financial Crisis, European Constitution, Brexit, Pandemic.

\section{Introducción}

La Unión Europea (UE) es el proceso de integración más exitoso de la historia de la sociedad internacional y el más imitado por los Estados de otras regiones del planeta que persiguen unirse para lograr beneficios y 
profundizar aún más en la cooperación internacional; pero también es el que más avatares y acontecimientos imprevisibles ha sufrido en el largo proceso de su conformación y consolidación política y jurídica. Cada una de las vicisitudes suponen peldaños de una, por ahora, interminable escalera que conduce a la plena integración europea y que han puesto a prueba el ingenio, la creatividad $\mathrm{y}$, sobre todo, el afán de superación de este particular producto humano que tiene su origen en un objetivo tan valioso como complejo: impedir un nuevo enfrentamiento entre europeos, integrar su economía y afianzar la solidaridad en el continente europeo. Eso se ha conseguido por el momento. Como lo han señalado destacados pro europeístas españoles como Josep Borrell: "Nada está escrito, salvo la historia del éxito que hasta ahora ha sido el proyecto europeo. Un proyecto que ha pacificado el continente, integrado su economía y ayudado a recuperar el retraso de los que, como nosotros, cogimos el tren en marcha"3.

Pero como la historia está repleta de ejemplos que demuestran que siempre es posible la regresión, la UE debe continuar su trayectoria para impedir una guerra o cualquier tipo de conflicto armado en territorio europeo y para promover, a pesar de las crisis, la estabilidad política y la prosperidad económica que, con su más y sus menos, han disfrutado y disfrutan los países miembros y la mayoría de sus ciudadanos. En efecto, la UE se ha forjado en las crisis y progresa con y a pesar de ellas porque cada uno de los momentos de tensión o incertidumbre han sido una oportunidad para crear mejores mecanismos de gestión de futuros problemas y para demostrar el valor añadido que implica formar parte de este esquema de integración. En palabras de uno de los "Padres de Europa", Jean Monnet, en una de sus frases más célebres y repetidas, "los hombres sólo aceptan el cambio resignados por la necesidad y sólo ven la necesidad durante las crisis"4.

Como decíamos, la UE ha vivido numerosas etapas de crisis desde su creación como CEE, en 1957, que explican por qué el proceso dinámico de la integración ha sido más lento de lo que cabía esperar y por qué ha encontrado tantas dificultades en el camino hacia la plena integración. Algunas crisis han sido originadas desde dentro y han estado motivadas por ese obstinado afán de avanzar en el proceso de construcción europea más allá de lo que era posible o de lo que estaban dispuestos algunos Estados miembros, como el proyecto de Constitución Europea a principios del siglo XXI. En otras ocasiones, las crisis han sido generadas por uno de sus Estados miembros, como la del Brexit $^{5}$,

\footnotetext{
${ }^{3}$ Ramón Suárez Vázquez (Coord.), Construyendo la Constitución Europea. Crónica politica de la Convención de 2003, Real Instituto Elcano de Estudios Internacionales y Estratégicos, 2003, p. 14. En este monográfico participaron Josep Borrell, Carlos Carnero y Diego López Garrido.

${ }^{4}$ En 1943, J. Monnet manifestó en Argel su visión de una unión de Europa para recuperar y mantener la paz. En Jean Monnet; Memoires, Fayard, París, 1976.

${ }^{5}$ Recordemos que en 1965 Francia fue la protagonista de la "crisis de la silla vacía". Durante seis meses la República liderada, entonces, por Charles De Gaulle, no asistió a las votaciones del Consejo paralizando así muchas iniciativas del momento. Para volver a ocupar su puesto, Francia 
y otras han sido originadas por factores externos, como la crisis financiera del 2008 y la provocada por la irrupción de la pandemia de la Covid-19. Es más, en determinados momentos, la UE se ha enfrentado a crisis que se producen simultáneamente como la actual motivada por el Brexit, la Pandemia, y el crecimiento de los partidos populistas y xenófobos. En este artículo se analizan, de manera sumaria, cuatro de esos momentos que han ocurrido en el siglo XXI y que han puesto a la UE contra las cuerdas de su propia existencia, aunque también todos ellos la obligaron a aplicar la perspicacia más aguda para sobrevivir y seguir recorriendo la historia en su empeño por alcanzar la meta de la plena integración y solidaridad europeas.

Las crisis vividas por la UE han afectado a la Organización Internacional y a todos los Estados miembros, si bien el nivel de ensañamiento ha variado de unos casos a otros. Por lo general, son los países del sur los más afectados por las crisis que padece la Unión. Precisamente por ello son estos países los que, como veremos, solicitan con más determinación solidaridad y responsabilidad europea en los momentos de crisis. Desde luego, la falta de solidaridad supone un "peligro mortal para la Unión Europea", declaraba Jacques Delors, antiguo Presidente de la Comisión Europea, en relación con la crisis provocada por la Covid-196. Los cuatro momentos de crisis que relatamos y analizamos brevemente tuvieron orígenes diferentes $\mathrm{y}$, por orden cronológico, fueron los siguientes. Los dos primeros discurrieron en el primer decenio del siglo XXI: el proceso de Constitución europea y la crisis financiera mundial, y afectaron de manera primordial a aspectos políticos y económicos de la integración europea. Los dos segundos se enmarcan en el segundo decenio: el Brexit y la Pandemia de la Covid-19 y apresan cuestiones relativas a la salud, aunque no solo, y a la participación de los Estados miembros en el esquema de integración. En concreto, mientras la primera y la tercera crisis que se analizan fueron fundamentalmente políticas; la crisis de 2008 tuvo un origen financiero y la de la Covid-19 un origen sanitario con repercusiones en el campo político y económico. Todas ellas han generado, sin embargo, una crisis de identidad al poner en cuestión valores y principios de la UE, como son la solidaridad, la igualdad, la paz, la libertad, la cohesión social, el bienestar y el respeto por los derechos humanos, entre otros; y elementos claves de la integración como la libertad de circulación de la personas y políticas de la UE.

exigió la revisión de las funciones de la Comisión y las diversas modalidades de votación mayoritaria existentes. En "Historia de la Unión Europea: La crisis de la silla vacía", disponible en https://www. europaciudadana.org/historia-de-la-union-europea-la-crisis-de-la-silla-vacia/.

${ }^{6}$ Disponible en https://www.eldiario.es/internacional/gestion-economica-coronavirus-reabrireuropa_1_1105713.html.

Araucaria. Revista Iberoamericana de Filosofia, Politica, Humanidades y Relaciones Internacionales, año $22, \mathrm{n}^{\circ} 45$. Tercer cuatrimestre de 2020. Pp. 103-129. ISSN 1575-6823 e-ISSN 2340-2199 https://dx.doi.org/10.12795/araucaria.2020.i45.05 


\section{El anhelo de aprobar una Constitución Europea y sus efectos: Crisis política y de identidad en la Unión}

La UE terminaba el siglo XX con numerosos éxitos en clave política y económica y con una confianza evidente en sí misma que la impulsan a dar un paso decisivo para su futuro: el de la consolidación política real plasmada en un texto constitucional. En efecto, al inicio de la nueva centuria el proceso de integración económico, que comenzó en la década de 1950, se presentaba como un objetivo superado. Este hecho, y el avance político que se produce a partir del decenio de los noventa, va a favorecer que la clase política más creyente en la supranacionalidad apostara por el gran reto de la integración política y que todo ello tuviera una plasmación jurídica. Por lo tanto, el siglo XXI amanece con la esperanza de que el proceso de construcción europea se robustezca y que se produzca el salto cualitativo que llevara a la conclusión de un tratado que recogiera los aspectos constitucionales del sistema europeo que se había ido edificando a lo largo de los años.

En particular, en un clima de cierta euforia europeísta se planteó el diseño de una Constitución para el continente, un texto sin precedentes en su historia y que se consideró entonces esencial para que la Unión se fortaleciera y para responder con eficacia a los desafíos de la globalización. Unos desafíos que tenían que ver con el rebrote de los nacionalismos europeos y los sentimientos xenófobos, fruto de las olas inmigratorias; el desempleo, el terrorismo, la débil "identidad europea", entre otros; y de una manera especial el gran reto político que representaba la ampliación. A tal efecto, conviene recordar que, en 2004, la UE pasó de tener 15 a 25 Estados miembros. La ola de la quinta ampliación implicó el ingreso de la gran mayoría de los países de la Europa central y oriental y, por ende, el fin definitivo de la división europea o telón de acero, además de la conformación de uno de los mercados más potentes en la escena internacional. En ese momento, la respuesta que la UE proyecta a todas las fuerzas centrífugas que se han descrito es la definición y aprobación de un texto constitucional que permitiese que el proceso de integración europea avanzase hacia un modelo federal basado en los principios de subsidiaridad, unidad, diversidad y autonomía.

Sin embargo, desde el primer momento se comprobó que el proceso tendente a la casi plena integración política dirigido, en una primera fase, a conformar un modelo jurídico-político común, presentaba una serie de obstáculos que debía afrontar, sobre todo por la diversidad de identidades políticas $^{7}$, sociales, culturales; y por la asimetrías económicas existentes

${ }^{7}$ Las estructuras estatales de algunos países europeos, como Alemania, se basan en principios federales, mientras que otros son Estados centralizados políticamente y descentralizados administrativamente como Francia.

Araucaria. Revista Iberoamericana de Filosofí, Política, Humanidades y Relaciones Internacionales, año $22, \mathrm{n}^{\circ} 45$. Tercer cuatrimestre de 2020. Pp. 103-129. ISSN 1575-6823 e-ISSN 2340-2199 https://dx.doi.org/10.12795/araucaria.2020.i45.05 
entre los Estados miembros y, si se quiere, por la vitalidad que expresaban las identidades nacionales. En efecto, el proceso político se presentaba harto complicado y lento porque, en el fondo, "el reto era poner de acuerdo a 25 Estados en torno a una organización política" que fortaleciese la construcción europea y que, además, acordase unas reglas del juego que incorporaban componentes esenciales de supranacionalidad. El mismo enunciado del Tratado sobre la Constitución Europea, el Tratado por el que se establece una Constitución para Europa, expresó la sólida voluntad de enriquecer el proceso y de apuntar a cotas que, hasta entonces, no se habían alcanzado.

En diciembre de 2001 se celebró en Bruselas el Consejo Europeo de Läeken que aprobó la "Declaración sobre el futuro de la Unión" en la que se definían las etapas a seguir para avanzar paulatinamente en el proceso de integración política. Además, en la Declaración se convocó una Convención Europea, presidida por el dirigente francés Valéry Giscard d'Estaing, cuyo principal logro fue la redacción del Tratado Constitucional, un documento elaborado durante la Conferencia Intergubernamental de 2003/2004 en la que participaron "parlamentarios y representantes de los Gobiernos, actuales miembros de la Unión y candidatos a serlo, eurodiputados y de la Comisión Europea"9. Se estaban sentando las bases para que la UE, con la vista puesta a largo plazo en todo el continente, llevara a cabo un modelo de organización política que, hasta entonces, no se habría producido y que, en parte, se encuentra en los orígenes del ideario europeo. Haberlo logrado, hubiera supuesto una hazaña política de grandes dimensiones y un patrón a seguir en otros lugares del planeta. En cualquier caso, tras prolongados y complicados debates y reuniones, los países de la UE firmaron el Tratado que establecía una Constitución Europea y que tenía como principal finalidad dinamizar la gestión, reducir la excesiva burocracia y facilitar la toma de decisiones en el ámbito europeo pero, sobre todo, acoger la narrativa de que el esquema de integración estaba decidido a fundamentar una Organización Internacional que previese valores y principios constitucionales. En efecto, el nuevo texto constitucional pretendía sustituir a todos los tratados que se aprobaron desde el inicio de la integración del decenio de 1950 y sofocar, de una vez por todas, los intentos por debilitar la tarea integradora $^{10}$.

\footnotetext{
8 María Cristina Cabrales Baquero, "El Tratado por el que se establece una Constitución para Europa: ¿Una etapa crucial en el proceso de federalización?”, Papel Político, Vol. 11, núm. 1, Enero/Junio 2006, disponible en http://www.scielo.org.co/scielo.php?script=sci_arttext\&pid $=$ S0122-44092006000100012.

${ }^{9}$ Ramón Suárez Vázquez (Coord.), Op. Cit., p. 251.

${ }^{10}$ Todos los tratados firmados hasta entonces desaparecían, excepto el Tratado sobre Energía Atómica (EURATOM).
} 


\section{a) Algunos aspectos del contenido del Tratado Constitucional}

El nuevo texto constitucional, que desencadenó un amplio debate sobre el futuro y la dirección que debería tener el proceso de integración política de los próximos años, se caracterizó, sin embargo, por "poseer tanto elementos sustanciales propios de una Constitución, como también la forma y los procedimientos conforme a los tratados internacionales" ${ }^{\prime 1}$. Es decir, el Tratado se dotaba de una Carta de Derechos Fundamentales y establecía la división de poderes ejecutivo, legislativo y judicial, en un intento por asemejarse a los textos constitucionales de los Estados miembros, sin desprenderse todavía de los elementos que definen las relaciones de éstos en el seno de la integración europea y que se fundamentan, en esencia, en la participación activa de los Estados. Por esto, el texto señalaba que su entrada en vigor precisaba que este fuera ratificado por los Estados miembros, requisito necesario de cualquier tratado internacional, lo que ponía el acento más en la presencia y aceptación de los Estados que en la voluntad directa de los ciudadanos de Europa.

Como se ha señalado con reiteración, por entonces la UE había culminado la integración económica en sus aspectos básicos, quedando pendiente algunos asuntos relativos a la unión económica y monetaria, y se presentaba como una federación en diferentes ámbitos relacionados con la regulación del mercado interior o del comercio exterior. Sin embargo, los sectores que más comprometen la soberanía de los Estados y, por lo tanto, más reacios a que los Estados cedan sus competencias no estaban incluidos, con intensidad, en la organización jurídico-política que supone la UE. En verdad, el compromiso del texto constitucional fue desarrollar profundamente todas aquellas políticas que permitieran a la UE avanzar hacia una integración política real como es la política exterior, la defensa, los asuntos de justicia e interior, los derechos fundamentales, entre otros. Y, también, acordar un cambio de terminología que diera sentido constitucional a los avances que se iban produciendo en el esquema de integración. A través de las palabras y de los contenidos se buscaba, de manera contumaz, la edificación de una estructura constitucional que diera sentido, en los nuevos tiempos, a la realidad europea de integración.

De hecho, al analizar el contenido de la Constitución europea se comprueba que el Art. I-28 del Capítulo I del Título IV (Parte I) señala que la política exterior será una competencia exclusiva de un organismo propio de los Estados modernos como es un Ministerio de Relaciones Exteriores Europeo, y se advierte que el Título V (Parte III) se dedica en exclusiva a la Acción Exterior de la Unión, así como a los principios que determinarán su labor internacional ${ }^{12}$.

\footnotetext{
${ }^{11}$ María Cristina Cabrales Baquero, Op. Cit.

${ }^{12}$ Parte III; De las Políticas y el Funcionamiento de la Unión. Disponible en https://europa.eu/ european-union/sites/europaeu/files/docs/body/treaty_establishing_a_constitution_for_europe es.pdf.
}

Araucaria. Revista Iberoamericana de Filosofía, Política, Humanidades y Relaciones Internacionales, año 22, $\mathrm{n}^{\circ} 45$. Tercer cuatrimestre de 2020. Pp. 103-129. ISSN 1575-6823 e-ISSN 2340-2199 https://dx.doi.org/10.12795/araucaria.2020.i45.05 
También se aborda la creación de un Banco Central (Art. I-30 del Capítulo II) cuyo principal cometido sea la gestión de la política monetaria y la moneda común. Además, en el texto constitucional se aprecia un aumento evidente de las competencias y, por ende, de la legitimidad de las principales instituciones de la UE, entre ellas el Consejo, el Parlamento y la Comisión Europea ${ }^{13}$. Junto a los temas señalados, cabe destacar también que, durante la elaboración del texto constitucional, se discutió la posibilidad de incluir "el papel que la idea de Dios y los valores de la religión cristiana habían jugado en la conformación de la identidad europea"14. En este sentido, la solicitud planteada por el Papa Juan Pablo II y por algunos líderes de diferentes opciones políticas para que la futura Constitución europea contuviera una referencia a Dios y a la herencia cristiana chocó frontalmente con la de aquellos otros que defendían que la construcción europea era un proyecto laico desde sus orígenes y que debía seguir siéndolo. Al final, el debate se cerró con una conclusión consensuada que se limitó a citar, en el preámbulo de la Constitución, "la herencia cultural, religiosa y humanista". En definitiva, en la Constitución se omitió cualquier referencia a las raíces cristianas de Europa ${ }^{15}$.

La importancia de esta reflexión radica en que el texto constitucional buscaba denodadamente los asideros en los que sustentar una nueva etapa de la integración que supusiera un paso de gigante en la construcción europea, con base en los valores y principios que se habían ido desgranando desde hacía tiempo. Pero se trataba, en realidad, más allá de los contenidos que insistían en campos de actuación de los que ya se ocupaba la Unión, de conmover los componentes estructurales para que, con posterioridad, se pudiera abordar un modelo político singular en la escena internacional. La mera expresión de lo constitucional ayudaba a recorrer un empinado tramo del camino conducente hacia la plena integración europea. Esta es la razón de fondo que explica el desgaste que sufriría la UE en caso de no alcanzar sus objetivos y las anomalías que se podían producir en el desarrollo cotidiano de las políticas de la Unión.

\section{b) Razones del fracaso del texto constitucional}

Los acontecimientos posteriores a la aprobación del texto constitucional demostraron, sin embargo, que la euforia y el optimismo por avanzar hacia la integración política no estaban plenamente fundados como se creía, puesto que una parte de la ciudadanía europea y algunos Estados, a juzgar por lo que ocurrió después, no estaban preparados y tampoco anhelaban que se hiciera realidad tal propuesta. En otras palabras, el proceso de integración europea, que había experimentado avances decisivos, no estaba tan maduro como para

\footnotetext{
${ }^{13}$ Cfr. María Cristina Cabrales Baquero, Op. Cit.,

14 Ramón Suárez Vázquez, Op. Cit., p. 219.

${ }^{15}$ Cfr. ibídem, p. 221.
} 
que, sobre todo, la gran mayoría de los Estados miembros aceptaran que el nuevo texto constitucional se convirtiese en "la norma de normas"16. A esta razón de carácter general se suman otras que también explican el fracaso de la Constitución europea, como fue la dificultad que entraña poner de acuerdo a tantos países con intereses tan diferentes. La realidad evidenció, a la postre, que la elaboración de una Constitución que fuese común a 25 Estados, muchos de ellos plurinacionales, planteaba un desafío difícil de resolver y que precisaba un largo tiempo para alcanzar una solución satisfactoria.

De hecho, el debate sobre el texto constitucional generó tensión entre quienes veían en el federalismo el futuro político de la Unión y aquellos que percibían ese proyecto con escepticismo y desconfianza. En el primer grupo se encontraban países como Alemania, comprometido impulsor del modelo federal, y en el otro extremo países como Gran Bretaña, que política y militarmente se ha sentido siempre más identificado con Estados Unidos que con el propio proceso de integración europea. El arduo debate sobre la pretendida Constitución alertó, en todo caso, de las dificultades de mermar aún más las competencias de los Estados hasta límites insospechados y se trató de evitar que se produjeran estragos irreparables en la promesa de constituir una verdadera Europa unida. En cualquier caso, las visiones tan diferentes que se expresaron entonces no son imposibles de superar, pero se comprobó la necesidad de un cambio generacional que implique una evolución de la ciudadanía a favor de los valores europeístas. La integración política y económica sería insuficiente si se ignora que todo esquema de integración, sobre todo en los estadios en los que se halla la UE, precisa lo que se podría denominar una "integración psicológica". O, en otros términos, un formidable respaldo de la ciudadanía porque dispone de la convicción de la alta rentabilidad de la integración, lo que debe venir acompañado de la ausencia de reticencias por parte de los Estados miembros.

Existen otros factores, citados por la mayoría de los autores, que están entre las causas del fracaso de la definitiva aceptación de la Constitución y que tienen que ver con el texto en sí mismo y con el proceso político elegido para su ratificación. Sobre el primer factor, cabría recordar, en palabras de Alex Farnese, que el documento elaborado era "excesivamente técnico, su contenido era muy largo y farragoso, con artículos interminables de innumerables párrafos y apartados, que casi todo el mundo votó a ciegas"17. Este escollo quizá se podría haber superado si se hubiera abonado una decidida voluntad por aprobar el texto constitucional. Sin embargo,

\footnotetext{
${ }^{16}$ María Fernanda Penagos Forero y Jaime Humberto Ramírez Castro, “QQué pasó con la Constitución Europea? Razones que pudieron conducir a su no ratificación", Revista Auctoritas Prudentium, n. 2, 2009, p. 4.

${ }^{17}$ Alex Farnese, "El fracaso de la Constitución Europea", disponible en http://edumarvig.wordpress. com/2007/10/21/el-fracaso-de-la-constitucion-europea/, en María Fernanda Penagos Forero y Jaime Humberto Ramírez Castro; Op. Cit., p. 7.
}

Araucaria. Revista Iberoamericana de Filosofia, Politica, Humanidades y Relaciones Internacionales, año $22, \mathrm{n}^{\circ} 45$. Tercer cuatrimestre de 2020. Pp. 103-129. ISSN 1575-6823 e-ISSN 2340-2199 https://dx.doi.org/10.12795/araucaria.2020.i45.05 
el segundo factor será decisivo a la hora de explicar el estrepitoso fracaso del texto constitucional. Todo comenzó cuando los líderes europeos consideraron que lo más pertinente era que cada Estado miembro escogiera entre las dos fórmulas acordadas para la ratificación del tratado constitucional: por vía parlamentaria y por referéndum. El objetivo era que el periodo de ratificación tuviera lugar en un plazo máximo de dos años, para que la Constitución entrara en vigor en noviembre de 2006. Ahora bien, durante el proceso de ratificación del texto constitucional se observó la disparidad de posiciones que este tema generó entre los Estados miembros. Así, según el procedimiento aplicado y los resultados obtenidos, los Estados se clasificaron en países favorables a la Constitución y países contrarios. Dentro del primer grupo se encontraron Estados como Alemania, Austria, Bélgica, que eligieron la vía parlamentaria; y España ${ }^{18}$ o Luxemburgo que votaron "si" al texto constitucional en referéndum. En el segundo grupo destacaron aquellos Estados que manifestaron, en referéndum, su oposición al texto Constitucional, como Francia y los Países Bajos ${ }^{19}$. Por lo tanto, la disparidad de perspectivas sobre el texto constitucional fue clara entre los Estados miembros, "prevaleciendo una posición que, si bien no fue mayoritaria, logró paralizar el proceso de ratificación"20 de la Constitución y demostrar que el referéndum no era la mejor opción para aprobar el texto constitucional, por las características particulares que tiene este instrumento de participación popular. De hecho, sectores políticos europeístas no han dudado en criticar el procedimiento porque dejaba una decisión tan importante (definir el futuro de la UE) en manos del pueblo, al que no se le proporcionaron los elementos necesarios para conocer el contenido real del texto constitucional ${ }^{21}$. Incluso, tampoco se logró movilizar a las opiniones públicas ni generar la ilusión suficiente por avanzar hacia la integración política. Con lo cual, los rechazos mayoritarios en referéndum de Francia y Holanda frustraron definitivamente el texto constitucional, y la UE entró en una crisis de identidad, "la mayor que había sufrido en su medio siglo de historia"'22.

${ }^{18}$ Fue la primera vez que la ciudadanía española se pronunció en las urnas sobre una cuestión referida a la UE. Recordemos que el ingreso en la entonces CE, en 1986, no fue sometido a consulta popular.

${ }^{19}$ El 29 de mayo de 2005, el 55 por ciento de la ciudadanía francesa votó "No" a la Constitución europea. Días después, el 1 de junio, los Países Bajos rechazaban el texto constitucional (61 por ciento de los votantes).

${ }^{20}$ La entrada en vigor de la Constitución Europea requería la unanimidad. Cfr. María Fernanda Penagos Forero y Jaime Humberto Ramírez Castro, Op. cit., p. 24.

${ }^{21}$ Las diferentes campañas de promoción y capacitación no sirvieron para conocer el texto en sí, así como sus múltiples complejidades. Junto a las razones expuestas, otros autores, como Ignacio GarcíaValdecasas, achacan el rechazo del proyecto constitucional a "la irresponsabilidad de parte de la clase política, la ambigüedad del proyecto europeo y lejanía del mismo, el olvido del pasado reciente..., el fenómeno de la inmigración, la inseguridad ciudadana", entre otros. En Ignacio García-Valdecasas, "El rechazo al proyecto de Constitución Europea: un análisis retrospectivo", ARI, n 159, Instituto Real Elcano, 2005.

${ }^{22}$ Ibidem, p. 1.

Araucaria. Revista Iberoamericana de Filosofía, Politica, Humanidades y Relaciones Internacionales, año $22, \mathrm{n}^{\circ} 45$. Tercer cuatrimestre de 2020. Pp. 103-129. ISSN 1575-6823 e-ISSN 2340-2199 https://dx.doi.org/10.12795/araucaria.2020.i45.05 
La derrota del proyecto de Constitución europea dio paso a la aprobación del Tratado de Lisboa, del 13 de diciembre de 2007, un texto al que los expertos han tildado también de farragoso y complejo, que incluye casi el 100 por ciento de lo planteado en aquel tratado constitucional y que otorga más poder al Parlamento y a los tribunales de Justicia de la UE, en términos generales. Pero, con los matices que se quiera, la huella del texto constitucional quedó impresa en el contenido del Tratado de Lisboa y, desde luego, no se esfumaron algunos de los avances y las líneas de actuación que proponía el texto constitucional. Es verdad que el Tratado de Lisboa, "supone un giro sustantivo en la estrategia seguida formalmente por la UE desde el año 2000, tendente a reemplazar los Tratados por un nuevo texto único, de carácter constitucional", que sirviese "para caracterizar la nueva etapa, más avanzada, en el proceso de integración política de Europa" pero, sin duda, el retroceso que se produjo quedó compensando en parte porque "desde un punto de vista material, la aprobación del Tratado de Lisboa supone un importante paso hacia delante, por cuanto recoge en su texto el grueso de las innovaciones que aportaba el Tratado constitucional"23.

Durante los años posteriores al fracaso constitucional, y hasta que irrumpió la crisis financiera mundial, la mayoría de los ciudadanos europeos, desconectados de los debates y de la retórica de Bruselas, olvidaron por completo la propuesta más ambiciosa lanzada por la UE hasta entonces, y sin ser conscientes ni plantearse lo que se podía perder o ganar con ella. En todo caso, el sentimiento de fracaso fue evidente para los dirigentes europeos lo que dio paso a un periodo de reflexión, de dudas, de escepticismo y de parálisis del proyecto comunitario. Todo ello fomentó que en algunos países se reforzaran los nacionalismos y que rezumara una cierta actitud de aislacionismo, de poner por delante los intereses nacionales y las identidades propias frente al cosmopolitismo y la integración. Es más, se temió que se cumpliera el pronóstico lanzado por el Presidente de la Convención Europea, Giscard d'Estaing, cuando en 2002 declaró, en un ineficaz intento por insuflar ilusión al proyecto constituyente: "Soñemos con Europa. Si fracasamos, todo lo conseguido hasta entonces puede perderse" 24 . Afortunadamente esto no ocurrió. La UE superó la crisis constitucional y, de hecho, las élites políticas no tardaron en reaccionar y en admitir que el destino de la UE no tiene vuelta atrás y que el proceso de integración es un tren que tiene su propia velocidad y que para que las propuestas de gran calado no descarrilen, como la del texto constitucional, se precisa que los países, su clase política y sus ciudadanos circulen a la misma velocidad y por el mismo camino de los intereses comunes.

\footnotetext{
${ }^{23}$ Antonio Bar Cendón, "El Tratado de Lisboa y la reforma constitucional de la Unión Europea", Cuadernos Constitucionales de la Cátedra Fadrique Furió Ceriol, nº 60/61, 2007, pp. 192-193.

${ }^{24}$ Palabras pronunciadas por Giscard d' Estaing en la sesión inaugural del 28 de febrero de 2002; en Ramón Suárez Vázquez, Op. cit., p. 56.
} 
La decepción que provocó la reforma constitucional no ha apagado el ánimo $\mathrm{y}$, menos aún, ha agotado el interés porque se continúe avanzando en la integración europea. La amarga experiencia ha sido rentable en términos políticos y, hasta ahora, no ha detenido la faena tendente a que germine un nuevo modelo de "integración constitucional", a pesar de que esta palabra se haya convertido en maldita. Desde luego, han pasado 15 años y las nuevas generaciones no tienen conocimiento de ese momento tan aciago en el que fracasó una de las propuestas más atrevidas y ambiciosas realizadas por la UE en su larga historia. Plantear que hubiera ocurrido de haberse aprobado una Constitución para Europa es entrar en el terreno de las conjeturas, pero lo que sí parece evidente es que el rechazo al Tratado constitucional implicó, por el momento, el rechazo a una nueva UE y, en cualquier caso, una inflexión en el rumbo de su historia.

\section{La Crisis Financiera Mundial de 2008 y sus devastadores efectos}

La UE aún convaleciente, antes de recuperarse del shock del revés constitucional, tuvo que hacer frente a las primeras turbulencias económicas que auguraban una nueva crisis en el panorama europeo y que puso a prueba, una vez más, la unidad de la UE y su fortaleza. La caída de Lehman Brothers, en septiembre de 2008, se presentó como el acontecimiento que anunció el inicio de la peor crisis económica-financiera desde la Gran Depresión de 1929, tal y como la describió Ben Bernanke, ex-presidente de la Reserva Federal de los Estados Unidos ${ }^{25}$. A finales de 2008, la UE empezaba a acusar los efectos devastadores de una crisis que se manifestó con distinta intensidad en las economías europeas y de forma más acusada en la zona euro $^{26}$. De esta forma, la crisis que nació en Estados Unidos como riesgo bancario dio paso a la peor depresión sufrida en la UE en sus seis decenios de historia por las graves consecuencias sociales y humanas que generó para el bienestar de sus ciudadanos. Entre ellas, el aumento del paro en prácticamente todos los países y que amenazó seriamente la cohesión política y social de la Unión. En definitiva, el "Modelo Social Europeo", que implica objetivos y principios como la promoción del pleno empleo, la igualdad de oportunidades y la protección

${ }^{25}$ En https://expansion.mx/economia/2014/08/28/crisis-de-2008-peor-que-la-gran-depresion. Veáse Ben Bernanke, "The Macroeconomics of the Great Depression", disponible en https://ideas.

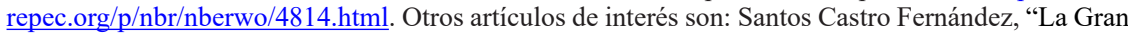
Recesión. Una Mirada desde Europa”, Documento Análisis, 31/2013, Instituto Español de Estudios Estratégicos, IEEE, Ministerio de Defensa, Madrid, 22 de mayo de 2013. Y David Vergara Figueras, "La respuesta de la UE a la crisis financiera", Business Review, $\mathrm{n}^{\circ} .249,2015$.

${ }^{26}$ El euro significó un gran avance en el proceso de integración, sin embargo, nació con ciertas debilidades porque su creación no fue acompañada de una política fiscal, una unión bancaria y una mayor integración económica y presupuestaria.

Araucaria. Revista Iberoamericana de Filosofia, Política, Humanidades y Relaciones Internacionales, año $22, \mathrm{n}^{\circ} 45$. Tercer cuatrimestre de 2020. Pp. 103-129. ISSN 1575-6823 e-ISSN 2340-2199 https://dx.doi.org/10.12795/araucaria.2020.i45.05 
social, sufrió una regresión durante la crisis, provocando serias fracturas en el proyecto comunitario.

Pero, además, la situación se complicó aún más y se generó un caldo de cultivo propicio para que, en plena recesión (2013), se reforzaran los nacionalismos y aumentara la tensión social y la xenofobia que pusieron en peligro el marco de convivencia de muchos Estados europeos. En algunos de los países de la Unión más gravemente afectados, la crisis económica y social se convirtió también en una crisis de tipo político que favoreció la aparición de líderes populistas y el aumento de los movimientos extremistas. Entre los países que sufrieron más directamente los efectos negativos de la crisis destacan Grecia, Irlanda, España y Portugal, entre otros. Todos ellos llegaron a esta etapa gravemente endeudados y con un alto nivel de desempleo, lo que les obligó a acomodar el consumo interno y a que, desde la Comisión Europea, conjuntamente con el BCE y el FMI, se acudiera con diferentes fórmulas al "rescate" financiero ${ }^{27}$. En esencia, una crisis financiera que se extendió a todo el ámbito económico y que, al mismo tiempo, erosionó los parámetros políticos tradicionales en los que se sustenta la UE.

La crisis no tuvo su origen en Europa, pero los Estados miembros de la Unión y las instituciones comunitarias tuvieron que actuar para debilitar y sosegar sus consecuencias y avanzar hacia la consolidación de la Unión Económica y Monetaria. Es más, desde que en 2008 se hizo visible la gravedad de la situación, la UE se presentó a sí misma como un actor clave en la respuesta global a la crisis y un protagonista útil para cualquier reforma de la arquitectura financiera mundial. En esos momentos, algunos líderes europeos se dedicaron a relatar los logros de la UE de los últimos 50 años y sus compromisos con la justicia social y la solidaridad, a fin de justificar su posición de liderazgo en el escenario mundial. Así, el premier británico Gordon Brown llegó a declarar en el Parlamento Europeo, en marzo de 2009, que la UE se encuentra "en una posición única" para liderar la "construcción de una sociedad realmente global, sustentable para todos, segura para todos y justa para todos" ${ }^{28}$. En definitiva, apostar por el modelo social europeo, proclamado en el Tratado de Lisboa, uno de cuyos fundamentos es la economía social y cuyo objetivo

\footnotetext{
${ }^{27}$ Un total de ocho Estados miembros de la UE recibieron ayuda financiera. La Troika, conformada por la Comisión Europea, el BCE y el FMI, fue una solución ad hoc que se adoptó bajo la presión de la crisis económica. La Troika fue creada por los Jefes de Estado y de Gobierno de la zona euro, mediante Decisión de 25 de marzo de 2010.

${ }^{28}$ Desde el comienzo de la crisis se elaboraron distintos informes que insistían en la necesidad de apostar por la cooperación europea y no en las soluciones unilaterales de los países. Uno de esos informes fue el Informe del Grupo de Expertos de Alto Nivel presidido por Jacques Laroisiére (2009) y elaborado por mandato de la Comisión Europea. Véase Mirjam Van Reisen, Louisa Vogiazides y Simon Stocker, "Respuesta europea a la crisis económica y financiera mundial", 2009, disponible en http://www.socialwatch.org/es/node/921.
} 
común es "alcanzar un equilibrio basado en la interdependencia activa entre el crecimiento económico y la solidaridad social" (Parlamento Europeo, 2006) ${ }^{29}$.

Parece evidente, en consecuencia, que desde las instituciones europeas e incluso desde los propios Estados se insistía en que la solución para abordar la difícil etapa era más Europa y que solamente a través de la acción coordinada de los Estados miembros y de la UE se podía impedir una recesión más profunda ${ }^{30}$. A nivel europeo, el esquema se concretó en un Plan de Recuperación Económica con el que la Comisión perfiló la respuesta global a la crisis mundial y definió una actuación colectiva, como UE, para superar la crisis económica y financiera. Este Plan de Recuperación, que apeló a los principios de solidaridad y justicia social, se centró en una inyección de poder adquisitivo en la economía con objeto de incrementar la demanda y generar confianza. Así, a finales de 2008, la UE presentó un programa de estímulo de miles de millones de euros mientras las principales economías europeas activaron diferentes planes nacionales. Sin embargo, la brutal recesión que experimentaron algunas economías obligó a que la UE aprobase medidas más drásticas como los Planes de Rescate. Para ello se activaron distintos instrumentos y mecanismos de ayuda financiera. Entre ellos destacan: 1) El Mecanismo Comunitario de Ayuda Financiera a Medio Plazo (en adelante MEDE), destinado a ayudar a aquellos Estados miembros que carecían de liquidez y tenían problemas para acceder a los mercados ${ }^{31}$. Este mecanismo, creado en 2012, concedió préstamos a países como España, Chipre y Grecia, entre otros; 2) El Mecanismo Europeo de Estabilización Financiera (MEEF); y 3 ) El Fondo Europeo de Estabilidad Financiera (FEEF) ${ }^{32}$. Ambos dirigidos también a ofrecer a los Estados miembros de la Unión, previa solicitud, una asistencia financiera en forma de préstamos o de apertura de líneas de crédito. Países como Irlanda, Grecia y Portugal acudieron a estos instrumentos ${ }^{33}$.

También se adoptaron medidas que estaban encaminadas a implantar una auténtica Unión bancaria, a lograr una mayor armonización fiscal e impulsar

\footnotetext{
${ }^{29}$ Fernando Casas Mínguez, "La crisis de la Unión Europea, de los Estados europeos de Bienestar y del Modelo Social Europeo (MSE) con especial referencia a las políticas de inclusión”, VII Informe sobre exclusión y desarrollo social en España, Documento de Trabajo 5.1., 2014, p. 2.

${ }^{30}$ Véase el interesante trabajo de Elena C. Díaz Galán, "Balance de las medidas financieras adoptadas para afrontar la crisis económica de la Unión Europea”, Anuario de la Facultad de Derecho, Universidad de Extremadura, $n^{\circ}$. 32, pp. 2015-2016. En este artículo la autora analiza las respuestas de la UE a la crisis así como su eficacia para la recuperación económica de la región.

${ }^{31}$ Baudilio Tomé Muguruza, "La respuesta de la Unión Europea a la crisis económica y el papel de las Instituciones de control externo", Revista Española de Control Externo. Disponible en https://www. tcu.es/repositorio/f1b6ec5d-02cf-479c-95a1-e3170c677137/N43\%20TOME\%20RESPUESTA.pdf.

${ }^{32}$ No obstante, tras la creación del MEDE, la FEEF dejó de prestar asistencia financiera. En https:// www.europarl.europa.eu/factsheets/es/sheet/91/la-asistencia-financiera-a-los-estados-miembros-dela-union.

${ }^{33} \mathrm{La}$ economía griega fue, con seguridad, la más afectada por la crisis y lo que explica, por tanto, que desde 2010 se pusieran a su disposición los diferentes programas de ayuda creados con el fin de que el país helénico pudiese cumplir con sus obligaciones financieras. Eso sí, la ayuda estuvo condicionada al cumplimiento de un complejo plan de reformas por parte del gobierno griego bajo la supervisión de la UE.
} 
el crecimiento. En definitiva, el propósito era alcanzar a medio y largo plazo una arquitectura más sólida de la Unión Económica y Monetaria (UEM). Así, en diciembre de 2012, el Consejo dio un salto cualitativo hacia la Unión Bancaria en el seno de la UE a través de la creación del Mecanismo Único de Supervisión (MUS) ${ }^{34}$. Junto a lo señalado, la UE también estableció medidas dirigidas a "regular el sector financiero y mejorar la gobernanza económica; llevar a cabo reformas estructurales, estimular la inversión...y establecer métodos para gestionar y prevenir mejor posibles crisis" ${ }^{35}$. Todas estas medidas impulsaron de forma decidida la UEM, pero no obstante sigue siendo un proyecto en formación que precisa de una mayor consolidación para que el Euro se convierta en una moneda fuerte y para que se refuerce su papel internacional.

Los Estados miembros de la UE también se comprometieron en la respuesta a la crisis financiera. En concreto, la solución aplicada por la mayoría de los países afectados por la recesión consistió en políticas económicas basadas en la austeridad y el control financiero, es decir programas de ajuste presupuestario y de reducción de los gastos sociales; además de recortes y congelaciones salariales. Todas estas medidas tuvieron un impacto directo e indirecto en los niveles de empleo y en cuestiones sociales. Precisamente, las consecuencias generadas por los PNR (Planes Nacionales de Reforma), de 2012, llevaron a los expertos a la conclusión de que la combinación de las medidas de austeridad, que impactan en los colectivos más vulnerables, y el bajo nivel de crecimiento económico, generaron un aumento de la pobreza y la exclusión social. En el caso español, por ejemplo, el Gobierno subió los impuestos y aplicó recortes presupuestarios con el objetivo de equilibrar la relación deuda bruta/PIB (imposiciones del BCE y FMI) ${ }^{36}$.

Lo relevante es que, desde el comienzo de la crisis, en particular la Comisión Europea y los Estados miembros de la UE tomaron una serie de medidas para contrarrestar los efectos del declive económico. No obstante, el balance realizado, en una primera fase, no se puede calificar de positivo. Las consecuencias generadas por la recesión económica y las medidas aplicadas hicieron que algunos autores y países señalaran que la crisis no se había traducido en estímulos económicos y que se había perdido una buena oportunidad para consolidar los objetivos del Tratado de la Unión y la Carta de los Derechos Fundamentales. Desde luego, en la primera etapa de la crisis no se favoreció el desarrollo de políticas dirigidas a crear sociedades cohesionadas y respetuosas

\footnotetext{
${ }^{34}$ Cfr. Baudilio Tomé Muguruza, Op. cit., p. 91. Véase "Unión Bancaria. Conclusiones del Consejo Europeo pertinentes". Consejo de la Unión Europea, p. 9, disponible en https://www.consilium. europa.eu/media/21532/sn04481es14.pdf.

${ }^{35}$ Comunicado de prensa, 9 de agosto de 2017, Comisión Europea. Diez años después del comienzo de la crisis: vuelta a la recuperación gracias a la intervención decisiva de la UE. Disponible en https:// ec.europa.eu/commission/presscorner/detail/es/IP $17 \quad 2401$

${ }^{36}$ Enrique Casais Padilla, "La respuesta a la crisis en la UE: España camino de su década perdida", Problemas del desarrollo, Vol. 42, núm. 166, julio/septiembre 2011.
} 
con los derechos humanos ni una economía social de mercado, como lo indica el Tratado. Es más, algunos autores no dudaron en alertar que la crisis fue aprovechada por la Troika para dar marcha atrás al proceso de construcción europea, "convertir en retórica los valores de la Unión y liquidar algunas de las políticas económicas, sociales y de empleo de la UE" ${ }^{37}$, que habían mejorado sustancialmente el bienestar de los trabajadores europeos.

Estas opiniones cobraron una inusitada fuerza en un primer momento por el aumento del desempleo y la pobreza, de las desigualdades y por el desapego que se vivió en los años más duros de la crisis por parte de la mayoría de la ciudadanía europea. Sería ingenuo no reconocer que las consecuencias de la crisis financiera fueron palpables en la UE por afectar directamente a la línea de flotación de sus principios económicos y sociales, cuyos objetivos se basan en disminuir las asimetrías económicas entre las regiones y los países; y promover la justicia social y la solidaridad ${ }^{38}$. Con todo, una crisis eminentemente económica evolucionó rápidamente para convertirse, también, en una crisis de los valores europeos y, por ende, en una crisis política.

Sin embargo, la situación económica comenzó a mejorar sensiblemente a partir de 2015. Dos años después se pudo constatar que la intervención de la UE había sido decisiva a través de los diferentes planes y políticas, así como la acción individual de los Estados afectados y que se empezaban a recoger los frutos de unas decisiones ampliamente denostadas. En efecto, la economía de la UE crecía en términos generales y de forma consecutiva desde los últimos años, el desempleo había disminuido con respecto a 2008, las inversiones aumentaban, y las finanzas públicas gozaban de buena salud ${ }^{39}$. Con independencia de los errores e improvisaciones cometidos por la UE y sus Estados miembros, queda claro que también se adoptaron decisiones y políticas que resultaron adecuadas para debilitar los impactos sobre la economía de la crisis, para contribuir a equilibrar los mercados financieros y para evitar y sortear males mayores. Por lo menos, como lo señaló Elena C. Díaz Galán,

\footnotetext{
"puede defenderse que se ha realizado un gran esfuerzo (...) por evitar una quiebra del sistema financiero, tanto a nivel mundial como europeo, y sentar los fundamentos de la recuperación económica y por avanzar en la construcción de la Unión Europea" ${ }^{40}$.
}

\footnotetext{
${ }^{37}$ Gregorio Rodríguez Cabrero, "Estado de bienestar en España: transformaciones y tendencias de cambio en el marco de la Unión Europea”, VII Informe sobre exclusión y desarrollo social en España, 2014, p. 309.

${ }^{38}$ En concreto, la lucha contra la exclusión y la pobreza forma parte de la política social europea desde, al menos, el primer programa europeo de lucha contra la pobreza de la década de 1970 .

${ }^{39}$ Comunicado de prensa, 9 de agosto de 2017, Op. Cit.,

${ }^{40}$ Elena C. Díaz Galán, Op. Cit., p. 5.
} 


\section{EI Brexit: Una nueva oportunidad para profundizar en la integración mediante la superación de la crisis}

Es infrecuente que un Estado abandone una Organización Internacional y, menos aún, cuando participa en un esquema de integración y no en solo un espacio para la cooperación. Por lo tanto, cuando esto sucede se trata de una situación excepcional que tiene, en principio, profundas consecuencias tanto para el Estado en cuestión como para la propia Organización a la que pertenece y que se dejan sentir, sobre todo, en el campo político y económico pero, también, en otros sectores de la actividad social y de las relaciones internacionales. Esta situación excepcional se produjo precisamente cuando el 23 de junio de 2016 se celebró el Referéndum en el Reino Unido de Gran Bretaña e Irlanda del Norte sobre la permanencia de este Estado a la UE y cuyo resultado, repetido hasta la saciedad, fue favorable para los partidarios de abandonar la Unión por un apretado margen del 51,9\% a favor y 48,1\%, en contra, con una participación del 72,2\% del electorado. La decisión de abandonar la Unión se consumará algunos años después, el 31 de enero de 2020. Los distintos aspectos de una decisión de este tipo han sido y todavía son objeto de múltiples análisis doctrinales y políticos pero la intención en este estudio es aclarar uno de los efectos que el abandono por el Reino Unido tiene para la propia Organización y palpar cómo este suceso constituye uno de los avatares a los que se ha enfrentado la UE en el siglo XXI, del que ha salido airosa.

Es probable que los resultados del análisis fueran distintos en función de los sectores que se examinen de las relaciones entre el Reino Unido y la UE, de tal manera que, en unos supuestos, el abandono británico desvanece o debilita políticas de la Unión, o erosiona la visión trasatlántica que aporta el Reino Unido; y, en otros casos, la salida del Reino Unido pudiera favorecer, por ejemplo, una política migratoria más coherente y eficiente al no tener que contar con un país que tradicionalmente se ha opuesto a las políticas de la Unión en esta materia, o fortalecer la política social. Son muchas las consecuencias políticas, económicas, sociales, en política exterior, en el campo de la seguridad o en materia ambiental que se pueden extraer de la retirada del Reino Unido, pero lo importante es detectar si el balance de la decisión británica de abandonar la UE encarna una crisis insuperable para la UE, representa un escollo que se puede superar o, incluso, supondría una oportunidad para avanzar más rápido en el proceso de construcción europea. Sin entrar en el estudio detallado de todas estas cuestiones, y muchas más, cuya importancia no debe ser postergada, no compartíamos la opinión de que la salida del Reino Unido de la UE reporta graves inconvenientes para el devenir de esta Organización y advertimos que no pone en tela de juicio la integración en Europa. El principal aspecto que 
debe preocupar, más allá de los efectos comerciales o de integración política y social, es si el comportamiento del Reino Unido podría venir acompañado de otros supuestos y excitar así el desánimo por la integración europea.

El Brexit constituye un precedente de alto significado en el devenir de la UE desde su creación como proyecto de integración, por lo que no cabe menospreciar que, por primera vez con toda intensidad, un país ha decidido abandonar la UE lo que haría meditar sobre las eventuales ventajas de la retirada y los probables inconvenientes de la permanencia. Asimismo, el abandono británico provoca un deterioro en la imagen de la Organización que, sin duda, genera un desgaste en la posición que ocupa la UE en la escena internacional. El antecedente de la retirada de Groenlandia que, a partir de 1985, dejó de ser un territorio en el que se aplicaba el Derecho de la Unión no es equiparable ni comparable al Brexit por la entidad política, económica y de proyección internacional aunque, sin embargo, debe ser valorado en la medida en que este precedente sentó las bases del contenido de las reglas que en la actualidad administran la retirada de cualquier Estado Miembro o, como se ha dicho, es un antecedente "relevante, pues fue la primera ocasión en la que se aplicó un procedimiento similar al introducido casi treinta años después en el TUE"41.

Las consecuencias del mal precedente que supone el Brexit deben ser matizadas puesto que la UE se resiente de modo distinto en razón de quienes son los Estados que tomaran la decisión de apartarse del proceso de integración y de las circunstancias en las que se produjera esa decisión. Algunos aspectos permiten entender que el abandono del Reino Unido, siendo un hecho de trascendencia, no ha tenido ni tendrá consecuencias que pongan en entredicho los componentes básicos del esquema de integración o, por lo menos, que la UE dispone de la capacidad necesaria para enfrentar y superar los efectos de todo tipo que produce la retirada del Reino Unido. Más todavía, no se debería sofocar el argumento que predica que la UE se robustece sin el Reino Unido y que la decisión británica puede resucitar el empuje integrador.

Primero, la retirada del Reino Unido de la Organización europea se produce de manera bastante ordenada, a pesar del turbulento, ruidoso e incierto discurrir de las negociaciones que tuvieron lugar para hacerla efectiva; y, además, el resultado final es que se mantienen vínculos entre las dos partes, de tal modo que no puede hablarse de una ruptura abrupta de relaciones. Estos dos aspectos aligeran el peso de los efectos negativos que una decisión tan insólita, como el abandono, produce necesariamente. Una de las enseñanzas que proporciona el Brexit será que, con pleno respeto al derecho, los Estados pueden retirarse de una Organización de integración y, con ello, se suavizan sobremanera las consecuencias de una situación de esta índole. En este caso, el artículo 54 del

${ }^{41}$ Soledad Torrecuadrada García-Lozano “¿Qué es el Brexit?: Origen y posibles consecuencias”, Anuario Mexicano de Derecho Internacional, vol.17 México ene./dic. 2017. 
Convenio de Viena sobre el Derecho de los Tratados, de 1969, regula los casos en los que un Estado puede dar por terminada su participación en un Tratado y dispone expresamente que "la terminación de un tratado o el retiro de una parte podrán tener lugar: a) conforme a las disposiciones del tratado (...)". Esto fue precisamente lo que ha sucedido en el caso del Brexit. El artículo 50 del Tratado de la UE, de 2007, establece una "cláusula de retirada", que prevé un mecanismo y procedimiento específicos que aseguran la retirada voluntaria y unilateral de un Estado de la Organización. De los cinco párrafos que integran este precepto cabe destacar, ahora, los siguientes: Por un lado, el párrafo 1 estipula que "Todo Estado miembro podrá decidir, de conformidad con sus normas constitucionales, retirarse de la Unión". Una previsión así anuncia que la UE no descarta que se produzcan situaciones de este tipo; y la Organización se hace cargo de las consecuencias que se deriven de tal decisión. El innegable carácter excepcional que tiene el Brexit queda acotado por el componente de la previsibilidad, lo que revela la robusta voluntad de la Unión de superar cualquier situación en la que tenga lugar el abandono por parte de un Estado Miembro. Por otro lado, el párrafo 2 prescribe que

"El Estado miembro que decida retirarse notificará su intención al Consejo Europeo. A la luz de las orientaciones del Consejo Europeo, la Unión negociará y celebrará con ese Estado un acuerdo que establecerá la forma de su retirada, teniendo en cuenta el marco de sus relaciones futuras con la Unión (...)”.

Esta disposición, al tiempo que señala el inicio del procedimiento de retirada de un Estado Miembro, está orientada a debilitar o sofocar los efectos más negativos que produce, en principio, el abandono de una Organización de integración. Se pretende evitar o limitar el "efecto desbandada" y los comportamientos indómitos que estén dirigidos a romper todo tipo de relación con los antiguos socios, poniendo en entredicho la viabilidad de la integración europea $^{42}$.

En definitiva, estas dos previsiones dibujan un panorama muy distinto a lo que ha ocurrido en otros esquemas de integración, como sería el caso de UNASUR, en los que el abandono, suspensión o expulsión de algunos Estados miembros podría provocar, incluso, la desaparición de la Organización o su absoluta inviabilidad en el sistema regional en el que opera y en la escena internacional. Las negociaciones tendentes a permitir la salida del Reino Unido de la UE se han traducido en acuerdos que regulan las bases de la relación futura entre las partes y que, asimismo, trazan vínculos privilegiados entre los

\footnotetext{
${ }^{42}$ Un examen jurídico del acto de retirada conforme a las normas del Derecho Internacional y el Derecho Europeo en Araceli Mangas Martín "Cuestiones jurídicas del Brexit: notificación, plazos, formación de la voluntad, orientaciones y revocación”, Anuario Español de Derecho Internacional, vol. 34, 2018, pp. 813-831.
} 
antiguos socios. El resultado es, por lo tanto, un "abandono amistoso" en la medida en que prevé y regula las consecuencias, preserva lazos de cooperación en determinados sectores, y adivina las líneas de actuación en la colaboración futura. El carácter ordenado y regulado de la salida del Reino Unido de la UE es proclive a una relación de amistad, eludiendo al máximo las crisis que se producen en las dos partes ${ }^{43}$.

Segundo, el abandono del Reino Unido es mucho menos doloroso y, sobre todo, limita bastante las consecuencias en la UE puesto que tradicionalmente ha sido escasa la voluntad europeísta del Reino Unido o, en otras palabras, "nunca ha sido visto como un Estado europeísta"44. En pocas ocasiones, el Reino Unido ha expresado el anhelo de que se produzcan avances significativos en la construcción europea $y$, menos todavía, contribuir a logros significativos en la integración. La política exterior británica no ha tenido, en sus lineamientos, como pilar sustancial la pertenencia a esta Organización de integración porque ha repartido sus intereses políticos y económicos en una amplia gama de relaciones con otros Estados y regiones del planeta. Los líderes británicos, salvo algunas excepciones, no han asumido el compromiso de potenciar la UE y tampoco se han sentido integrados en el proyecto común europeo. Un somero recorrido histórico demuestra que el ingreso del Reino Unido en la Organización, en 1973, no se produjo pacíficamente en términos políticos, siendo así que, incluso, en 1975, se celebró un primer referéndum sobre la permanencia de este Estado en la Comunidad Económica Europea. En términos reales, el Reino Unido es un país que, en razón de lo que le correspondía, se incorporó tardíamente al proyecto europeo $\mathrm{y}$, asimismo, desde los inicios ha hecho públicas sus dudas de la conveniencia de permanecer en el esquema de integración. La enérgica identidad británica ha sido, con seguridad, incompatible con cualquier pérdida de soberanía estatal o nacional. De ahí que la decisión del 2016 se deba contabilizar como la "crónica de un abandono anunciado" lo que hace que sea menor el deterioro en la imagen de la UE en la escena internacional por perder a uno de sus miembros y, sobre todo, desde hace tiempo no se descartarse que la salida del Reino Unido se pudiera producir.

Por último, el grado de implicación del Reino Unido en la UE ha sido siempre menor en comparación con otros Estados, más allá de algunos componentes de la integración económica. Casi siempre, las autoridades de Londres han expresado un rechazo a todo avance de la integración en el campo político. El Reino Unido no ha liderado nunca el proceso de integración europea y habitualmente se ha mantenido al margen de ser protagonista de las principales decisiones de la Organización. Tampoco ha participado en aquellos

${ }^{43}$ Vid., Acuerdo sobre la retirada del Reino Unido de Gran Bretaña e Irlanda del Norte de la Unión Europea y de la Comunidad Europea de la Energía Atómica en https://eur-lex.europa.eu/legal-content/ ES/TXT/?uri=CELEX\%3A12020W\%2FTXT.

${ }^{44}$ Soledad Torrecuadrada García-Lozano, Op. cit. 
ámbitos que revelan una paulatina y profunda voluntad integradora por lo que, usualmente, ha sido un Estado que tenía la intención de reprimir los avances en la integración que se proponían y que llevaban a cabo otros países de la Unión. Sin entrar en detalles, algunos datos confirman esta aseveración. En el campo económico destaca la no adhesión del Reino Unido a uno de los componentes esenciales de la UEM como es la adopción de una moneda única europea. En el campo social, sobresale el tradicional rechazo de las autoridades británicas a la política social europea ${ }^{45}$; y en el campo político, se debe recalcar la no participación de los británicos en el acervo Schengen, que implica, entre otras cosas, la supresión de las fronteras entre los Estados miembros de la UE y fomenta la libre circulación ${ }^{46}$. En definitiva, se puede suscribir que "la insatisfacción o escepticismo británico no ha sido novedad. El Reino Unido fue siempre asociado a una posición crítica en distintas fases y aspectos del proceso europeo" ${ }^{47}$.

\section{La pandemia: más retos para la integración europea}

La irrupción de la pandemia de la Covid-19 con intensidad a partir de finales de 2019 tiene consecuencias de todo tipo y en todos los Estados de la comunidad internacional. La UE no es, por lo tanto, un actor privilegiado para sufrir con mayor énfasis los efectos negativos de la pandemia. Sin embargo, las consecuencias económicas y políticas, y sobre todo de carácter sanitario, que provoca la transmisión y propagación del virus se dejan sentir también en el quehacer de esta Organización de integración. Las respuestas que dé la UE a todo lo que se deriva de una pandemia de este tipo pondrán de relieve la capacidad que tiene la Organización para hacer frente a estas situaciones y, especialmente, evitar que los Estados miembros se sientan desamparados en las decisiones y políticas que adopten para superar las crisis que genera o, al menos, para suavizar los amplios efectos negativos que produce en la salud y en el campo económico. El Director General de la Organización Mundial de la Salud (OMS) decía que "la propagación mundial del virus ha desbordado los sistemas sanitarios y ha provocado una amplia perturbación social y económica" siendo extremadamente relevante que "la enfermedad se ha propagado rápidamente

${ }^{45}$ Algunos detalles de estos aspectos se pueden apreciar en Araceli Mangas Martín, "La retirada del Reino Unido de la Unión Europea”, Foro, Nueva época, vol. 19, n. 1, 2016, pp. 29-63.

${ }^{46}$ Aunque se debe recordar que "de hecho, a lo largo de estos años, el RU ha decidido incluirse en algunos aspectos relativos a la cooperación policial y judicial en materia criminal, en la lucha contra las drogas y en el Schengen Information System", Antonio Bar Cendón "El Reino Unido y la Unión Europea: Inicio y fin de una relación atormentada", UNED. Teoría y Realidad Constitucional, $\mathrm{n}^{\circ} .40$, 2017, p. 154.

${ }^{47}$ Josefina del Prado, “Implicancias del Brexit en la Unión Europea”, Agenda Internacional XXV, $\mathrm{n}^{\circ} 36,2018$, p. 51.

Araucaria. Revista Iberoamericana de Filosofia, Política, Humanidades y Relaciones Internacionales, año $22, \mathrm{n}^{\circ} 45$. Tercer cuatrimestre de 2020. Pp. 103-129. ISSN 1575-6823 e-ISSN 2340-2199 https://dx.doi.org/10.12795/araucaria.2020.i45.05 
por todos los rincones del mundo" ${ }^{48}$. Por lo tanto, la pandemia de la Covid-19 no representa una crisis específica de la UE pero esta Organización se ve obligada a colaborar con los Estados miembros y a proporcionar soluciones propias para impedir, sobre todo, los efectos más negativos. Todavía es pronto para valorar si la UE saldrá reforzada o debilitada por la tarea en la lucha contra la Covid-19 y sus consecuencias, pero se podrían relatar algunas conclusiones provisionales.

En primer lugar, el inicial desconcierto, en los meses de enero a marzo de 2020, que dio lugar a que cada uno de los Estados adoptara sus reglas y políticas particulares para luchar contra la pandemia, ha dado paso a una acción más común y concertada en el seno de la UE. Por esto, la Comisión Europea se atreve a decir que existe una "respuesta europea común a la pandemia de coronavirus" y que se está trabajando "para reforzar nuestros sistemas de salud pública y mitigar el impacto socioeconómico en la Unión Europea"49. Se ha entendido, con rapidez, que la UE debería tener protagonismo en las decisiones encaminadas a poner fin a la pandemia y a calmar los efectos que provoca en los Estados miembros. Por ahora, el enfoque adoptado ha sido establecer un marco de colaboración permanente con los Estados para coadyuvar en la implantación de las medidas nacionales que pudieran hacer frente a los innumerables riesgos que derivan de esta situación. Lo que se desprende, por lo tanto, es que corresponde primordialmente a los Estados, en función del reparto de competencias, combatir los efectos de la pandemia aunque, para ello, contarán con la ayuda de la UE. En esta línea, se pueden extraer dos conclusiones: La primera que la UE, al igual que los Estados, se vio sorprendida por una crisis sanitaria de tal magnitud que explica la tardía respuesta. En particular, en los inicios la UE descargó en los Estados miembros la tarea de combatir la enfermedad y decidir las medidas para su contención. Por lo menos, "la UE tardó en reaccionar cuando los efectos de la pandemia devastaban Italia y España debido a la mirada autárquica de sus Estados miembros (...)" ${ }^{\prime 50}$; La segunda es que la UE ha advertido que obligatoriamente debe actuar y ofrecer respuesta a la pandemia y, en especial, elaborar una posición común para que los Estados no tengan la impresión de que la Organización se ha desentendido de la consecuencias de esta crisis sanitaria. Es decir, es "importante coordinar una respuesta sanitaria y económica conjunta que daría fortaleza interna y ayudaría a Europa en su política exterior y a configurar la Europa geopolítica"s1.

${ }^{48}$ OMS, Actualización de la Estrategia frente a la Covid19, 14 de abril de 2020, Ginebra, 2020, pp. $1-2$.

${ }^{49}$ https:/ec.europa.eu/info/live-work-travel-eu/health/coronavirus-response es.

${ }_{50}$ Miguel Ángel Benedicto, "Los retos de Europa y su futuro tras la pandemia de la COVID-19", Instituto Español de Estudios Estratégicos, Documento de Opinión 72/2020, 26 de mayo de 2020, p. 9.

${ }^{51}$ Ibidem., p. 14.

Araucaria. Revista Iberoamericana de Filosofia, Politica, Humanidades y Relaciones Internacionales, año $22, \mathrm{n}^{\circ} 45$. Tercer cuatrimestre de 2020. Pp. 103-129. ISSN 1575-6823 e-ISSN 2340-2199 https://dx.doi.org/10.12795/araucaria.2020.i45.05 
En segundo lugar, hasta ahora no se puede decir que la UE no haya respondido satisfactoriamente a la crisis sanitaria y económica que se ha producido como consecuencia de la pandemia. Todo lo contrario. Salvo que los hechos posteriores lo desmientan, la UE se ha constituido en un refugio para los Estados miembros e, incluso, ha potenciado su imagen en la escena internacional, a diferencia de lo que ha sucedido con otros esquemas de integración de los que existen en el planeta. Las medidas que ha puesto en práctica la UE han sido de diverso tipo y orientadas esencialmente al sector sanitario, al campo económico y a facilitar y ordenar la movilidad. En palabras de la Organización "Desde el estallido de la COVID-19, la UE ha estado trabajando junto con sus Estados miembros para proteger la salud y el bienestar de sus ciudadanos y salvar vidas". En esta línea, "la respuesta de la UE a la COVID-19 se centra en cuatro prioridades: limitar la propagación del virus, garantizar el suministro de equipos médicos, promover la investigación de tratamientos y vacunas, (y) apoyar el empleo, a las empresas y la economía"52. Predomina, desde luego, lo sanitario y lo económico, pero no se descuidan otros campos en los que la pandemia podría tener efectos perniciosos, como es el caso de la repatriación de ciudadanos europeos, la regulación de los viajes y la movilidad desde las fronteras exteriores, la garantía en el suministro de equipos de protección, el apoyo y desarrollo de la investigación para al obtención y posterior distribución de vacunas.

En cualquier caso, la medida más destacada y excepcional ha sido, con seguridad, la adopción del Plan de Recuperación para Europa, el 21 de julio de 2020. Lo resumía, con acierto, el Presidente del Consejo Europeo, Charles Michel, al decir que "Los objetivos de nuestra recuperación pueden resumirse en tres palabras: la primera es convergencia; la segunda, resiliencia; y la tercera, transformación. Esto significa, concretamente, reparar el daño causado por la COVID-19, reformar nuestras economías y remodelar nuestras sociedades" $" 53$. Tiempo habrá para valorar los resultados de este ambicioso Plan de recuperación económica que esconde una firme voluntad de robustecer la convergencia política entre los Estados de la Unión, pero la aprobación de las medidas que incorpora el Plan de Recuperación es una buena base para sostener que la UE ha sido capaz de dar respuestas, en el espacio en que el actúa, a una crisis sanitaria con importantes consecuencias económicas, que se ha extendido por todo el planeta. Las cifras son realmente abrumadoras. La UE ha logrado aprobar "un paquete exhaustivo de 1824300 millones EUR que reúne el marco financiero plurianual (MFP) y medidas extraordinarias de recuperación por importe de 750000 millones EUR en el instrumento «Next

\footnotetext{
${ }^{52} \mathrm{https}: / / \mathrm{www}$. consilium.europa.eu/es/policies/coronavirus/.

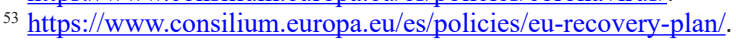


Generation UE»" ${ }^{54}$ siendo así que el Mecanismo de Recuperación y Resiliencia es una de las piezas clave para hacer efectivo el Plan de Recuperación.

\section{Consideraciones finales}

La UE se ha enfrentado a lo largo del tiempo a sucesivas crisis que tienen distinta naturaleza y contenido. El siglo XXI ha amanecido con retos y desafíos de envergadura para esta Organización Internacional y para sus Estados miembros pero, sobre todo, han tenido la capacidad de poner a prueba la resistencia de la UE como esquema de integración que pervive, a pesar de los avatares, y que está empeñada en continuar con el esfuerzo integrador. En tan solo una quinta parte de este siglo, la UE se ha tenido que enfrentar a una crisis económica de grandes dimensiones, a un riesgo sanitario hasta ahora desconocido por las actuales generaciones, a la retirada de la Organización de uno de los Estados que disponen de un mayor peso político y económico $\mathrm{y}$ al trance de tener que abandonar el anhelo connatural de construir una Europa unida en dimensiones constitucionales. Los peligros que se ciernen sobre la continuidad de la UE no han desaparecido, entre los que el "virus del nacionalismo" ocupa un lugar primordial. Sin embargo, la UE perdura como el principal ejemplo de los esquemas de integración que existen en el planeta y lo que queda por ver es si será capaz de ahondar todavía más en la integración en los próximos años.

La UE es la historia de una idea (proyecto de unión de Estados) que ha ido tomando cuerpo desde el primer día de su nacimiento y que no ha estado exenta de enemigos internos y externos, causantes principales de sus numerosas crisis. De cada una de las crisis la UE ha conseguido resurgir, gracias al esfuerzo de sus líderes políticos y de su ciudadanía, como un ave fénix y de cada una de ellas ha extraído enseñanzas que la sitúan en una posición de fuerza frente a futuros retos. Directamente vinculado a lo anterior, se puede afirmar que la UE es un proyecto que no tiene vía de retorno. En efecto, aunque el futuro de la UE es incierto, como lo es el de todas las construcciones humanas, es muy probable que continúe transitando durante los próximos decenios porque sus casi 70 años de historia avalan que todos sus Estados miembros han ganado en estabilidad política y prosperidad económica. Precisamente por ello, la gran mayoría de los países que la integran y de su ciudadanía no dudarán, como lo han hecho hasta ahora, en defender la fortaleza comunitaria frente a los embates y ataques internos y externos que se ciernen en el horizonte de la construcción europea.

Después de las crisis que se han relatado vendrán otras. De hecho, al margen de las crisis cíclicas, como son las económicas, es muy probable

\footnotetext{
${ }^{54}$ Ibidem.
} 
que la inmigración, el cambio demográfico, (la caída de la fertilidad y el envejecimiento de la población compliquen la consolidación del Estado de bienestar construido después de 1945) y las cuestiones conexas jueguen un papel decisivo en el futuro de la construcción europea y en el origen de futuras crisis. En este supuesto, serían crisis estructurales, por lo general más complejas y de difícil solución a corto plazo. Por ello es necesario afrontar cuanto antes la política de inmigración y, en general los retos relacionados con la integración política. En cualquier caso, a pesar de los desafíos y de las crisis que tiene que afrontar actualmente y que tendrá en un futuro, la UE cuenta con la veteranía de una historia forjada en dificultades que juega a su favor. En efecto, la UE dispone de muchos más mecanismos y de mayor experiencia e ideas que en ningún otro momento de su historia para salir de los trances en los que se ve envuelta y aumentar su cohesión y fortaleza. Hoy más que nunca el proceso de construcción europea debe presentarse como una unión de Estados que considere la crisis como una oportunidad para que sus miembros cooperen de forma activa en la vía de la recuperación. Después de todo, la experiencia ha demostrado que para resolver los problemas la receta es incidir más en los "intereses europeos" y menos en los "intereses nacionales". Es la única fórmula eficaz que existe para que Europa continúe siendo un actor clave en este mundo global. Por ello, es fundamental impulsar el avance de la UE, reforzar su dimensión política y adoptar medidas de mayor compromiso. Sería un grave error que la UE se situara en una actitud de placidez, conformismo y ensimismamiento por lo logrado hasta ahora. 


\section{Referencias bibliográficas:}

Bar Cendón, Antonio "El Reino Unido y la Unión Europea: Inicio y fin de una relación atormentada", UNED. Teoría y Realidad Constitucional, $\mathrm{n}^{\circ} .40$, 2017.

Bar Cendón, Antonio, "El Tratado de Lisboa y la reforma constitucional de la Unión Europea", Cuadernos Constitucionales de la Cátedra Fadrique Furió Ceriol, no 60/61, 2007.

Benedicto, Miguel Ángel, "Los retos de Europa y su futuro tras la pandemia de la COVID-19", Instituto Español de Estudios Estratégicos, Documento de Opinión 72/2020, 26 de mayo de 2020.

Cabrales Vaquero, María Cristina, "El Tratado por el que se establece una Constitución para Europa: ¿Una etapa crucial en el proceso de federalización?", Papel Político, Vol. 11, núm. 1, Enero/Junio 2006, disponible en http://www.scielo.org.co/scielo.php?script=sci arttext\&pid $=\mathrm{S} 0122-44092006000100012$.

Casais Padilla, Enrique, "La respuesta a la crisis en la UE: España camino de su década perdida", Problemas del desarrollo, Vol. 42, núm. 166, julio/ septiembre 2011.

Casas Mínguez, Fernando, "La crisis de la Unión Europea, de los Estados europeos de Bienestar y del Modelo Social Europeo (MSE) con especial referencia a las políticas de inclusión", VII Informe sobre exclusión y desarrollo social en España, Documento de Trabajo 5.1., 2014.

Castro Fernández, Santos, "La Gran Recesión. Una Mirada desde Europa", Documento Análisis, 31/2013, Instituto Español de Estudios Estratégicos, IEEE, Ministerio de Defensa, Madrid, 22 de mayo de 2013.

Farnese, Alex, "El fracaso de la Constitución Europea", disponible en http:// edumarvig.wordpress.com/2007/10/21/el-fracaso-de-la-constitucioneuropea/, Revista Auctoritas Prudentium, nº. 2, 2009.

García-Valdecasas, Ignacio, "El rechazo al proyecto de Constitución Europea: un análisis retrospectivo", ARI, no 159, Instituto Real Elcano, 2005.

Mangas Martín, Araceli "Cuestiones jurídicas del Brexit: notificación, plazos, formación de la voluntad, orientaciones y revocación", Anuario Español de Derecho Internacional, vol. 34, 2018.

Mangas Martín, Araceli, "La retirada del Reino Unido de la Unión Europea", Foro, Nueva época, vol. 19, no. 1, 2016.

Monnet, Jean, Memoires, Fayard, Paris, 1976.

OMS, Actualización de la Estrategia frente a la Covid19, 14 de abril de 2020, Ginebra, 2020. 
Penagos Forero, María Fernanda y Ramírez Castro, Jaime Humberto, “QQué pasó con la Constitución Europea? Razones que pudieron conducir a su no ratificación", Revista Auctoritas Prudentium, nº. 2, 2009.

Prado, Josefina del, “Implicancias del Brexit en la Unión Europea”, Agenda Internacional XXV, $\mathrm{n}^{\circ} 36,2018$.

Rodríguez Cabrero, Gregorio, "Estado de bienestar en España: transformaciones y tendencias de cambio en el marco de la Unión Europea”, VII Informe sobre exclusión y desarrollo social en España, 2014.

Suárez Vázquez, Ramón (Coord.), Construyendo la Constitución Europea. Crónica política de la Convención de 2003, Real Instituto Elcano de Estudios Internacionales y Estratégicos, 2003.

Tomé Muguruza, Baudilio, "La respuesta de la Unión Europea a la crisis económica y el papel de las Instituciones de control externo", Revista Española de Control Externo. Disponible en https://www. tcu.es/repositorio/f1b6ec5d-02cf-479c-95a1-e3170c677137/N43\%20 TOME\%20RESPUESTA.pdf.

Torrecuadrada García-Lozano, Soledad “¿Qué es el Brexit?: Origen y posibles consecuencias", Anuario Mexicano de Derecho Internaciona, vol.17 México ene./dic., 2017.

Van Reisen, Mirjam, Vogiazides, Louisa y Stocker, Simon, "Respuesta europea a la crisis económica y financiera mundial", 2009, disponible en http:// www.socialwatch.org/es/node/921.

Vergara-Figueras, David "La respuesta de la UE a la crisis financiera", Business Review, no 249, 2015. 
